\title{
Protected bronchoalveolar lavage in the diagnosis of ventilator-associated pneumonia
}

\author{
B. Barreiro*, J. Dorca*, F. Manresa*, I. Catalá**, L. Esteban*, \\ R. Verdaguer ${ }^{+}$, F. Gudiol++
}

Protected bronchoalveolar lavage in the diagnosis of ventilator-associated pneumonia. B. Barreiro, J. Dorca, F. Manresa, I. Catalá, L. Esteban, R. Verdaguer, F. Gudiol. @ ERS Journals Ltd 1996.

ABSTRACT: The aim of this study was to evaluate the diagnostic efficacy of protected bronchoalveolar lavage (PBAL) in ventilator-associated pneumonia (VAP), and to determine the effect of antibiotic therapy on its microbiological and cytological results.

We prospectively studied 102 episodes of suspected VAP in 93 patients. Subsequent follow-up confirmed VAP in 35 of the $102(34 \%)$ cases. In 55 of the $102(55 \%)$ VAP was ruled out, and the diagnosis remained undetermined in 12 of the $102(12 \%)$ episodes.

In the VAP group, 30 of the $35(86 \%)$ PBAL $\left(\geq 10^{4}\right.$ colony-forming units (cfu) $\left.\mathrm{mL}^{-1}\right)$ cultures were positive. In the non-VAP group, 5 of the $55(9 \%)$ PBAL cultures were positive. A Giemsa stain of PBAL samples was performed in 32 of the 35 cases of VAP. Intracellular organisms (ICO) were found in 24 of the $32(75 \%)$ cases. Seven of the other eight cases without evidence of ICO were already on antibiotics. In the non-VAP group, ICO were present in only 1 out of $55(2 \%)$ cases. The mean ICO was significantly higher in the group who had not received antibiotics when compared with those patients previously treated for less than $48 \mathrm{~h}(\mathrm{p} \leq 0.01)$ and those treated for more than $48 \mathrm{~h}(\mathrm{p}=0.009)$.

The sensitivity of protected bronchoalveolar lavage quantitative cultures was $87 \%$ and the specificity $91 \%$. The sensitivity of cytological analysis for intracellular organisms was $75 \%$ and the specificity $98 \%$. According to our results, if the patient is already on antibiotics, the direct examination of protected bronchoalveolar lavage fluid is less reliable, although still helpful.

Eur Respir J., 1996, 9, 1500-1507.

\begin{abstract}
Serveis de *Pneumologia, **Anatomia Patològica, +Microbiologia i ${ }^{++}$Malalties Infeccioses, Hospital de Bellvitge, Departament de Medicina, Universitat de Barcelona, Spain.
\end{abstract}

Correspondence: F. Manresa

Servei de Pneumologia

Hospital de Bellvitge

Feixa Llarga s/n. 08907

L'Hospitalet de Llobregat

Barcelona

Spain

Keywords: Bronchoalveolar lavage protected specimen brush

ventilator-associated pneumonia

Received: May 21995

Accepted after revision January 201996

Supported by Grants awarded by the "Fondo de Investigaciones Sanitarias (FIS)" $\mathrm{n}^{\circ}$ 92/240 and "Fundació August Pi i Sunyer (FAPS)" 1992-93.
The precise diagnosis of ventilator-associated pneumonia (VAP) is often difficult. Clinical signs of pneumonia (fever, pulmonary infiltrates, purulent tracheobronchial secretions) may be found in other pathological processes [1-3], and present a low sensitivity and specificity. The culture of tracheal secretions is of low value because the colonization of the upper airways by potential pathogens in intubated patients is common [4].

Protected specimen brush (PSB) was introduced by WiMBERLEY et al. [5], and has improved the accuracy of the bacteriological diagnosis of pneumonia in ventilated [6-11] and nonventilated patients [12].

More recently, bronchoalveolar lavage (BAL) has been used in the investigation of bacterial pneumonia [13-17]. Chastre and co-workers [13, 14] described a technique to evaluate the presence of intracellular organisms (ICO) recovered by BAL, suggesting that the presence of $\geq 7 \%$ of cells containing ICO was highly suggestive of VAP. A new technique to avoid contamination of BAL using a protected balloon (PB) catheter was introduced by MEDURI and co-workers [18, 19], obtaining a high sensitivity and specificity in BAL microbiological and cytological analysis.
The use of antibiotic therapy affects the diagnostic value of PSB [2, 12] and BAL [15] quantitative cultures, and false positive and false negative results have been observed [2, 12, 15, 19].

We have conducted a prospective study with two main objectives: 1) to analyse the diagnostic efficacy of protected bronchoalveolar lavage (PBAL) using a protectedballoon catheter; and 2) to evaluate the effect of prior antibiotics on the quantitative cultures and the cytological examination (ICO) of PBAL.

\section{Methods}

\section{Study design}

From October 1991 to December 1992, a prospective study was performed on patients with suspected VAP to evaluate the diagnostic efficacy of PBAL. All patients were admitted to the Intensive Care Unit (ICU) of the Hospital de Bellvitge, Barcelona, Spain. The inclusion criteria were the existence of a new or persistent infiltrate 
in chest radiographs and one or more of the following: 1) temperature $\geq 38.5^{\circ} \mathrm{C}$; 2) leucocytosis with white blood cells (WBC) count $\geq 10,000$ cells $\cdot \mathrm{mm}^{-3}$; and 3 ) purulent tracheal secretions. The exclusion criteria were: 1) platelet count $\leq 50,000$ platelets $\cdot \mathrm{mm}^{-3}$; b) arterial oxygen tension $\left(\mathrm{Pa}_{\mathrm{a}} \mathrm{O}_{2}\right) 8.7 \mathrm{kPa}(\leq 65 \mathrm{mmHg})$ with inspiratory oxygen fraction $\left(F \mathrm{I}, \mathrm{O}_{2}\right) 1 ; 3$ ) haemodynamic shock (systolic blood pressure $<60 \mathrm{mmHg}$ ).

Based on antibiotic therapy, three groups were defined: 1) nonantibiotic group, patients who had never received antibiotics; 2) patients in whom new antibiotics were started after the onset of symptoms suggesting the presence of pneumonia $(<48 \mathrm{~h})$, before bronchoscopy specimens were obtained; and 3) patients who had been receiving antibiotics for a long period of time ( $>48 \mathrm{~h}$ ) for another infection (pulmonary or not) before the appearance of suspected pneumonia.

Informed consent for inclusion in this study, written or on witness, was obtained from direct relatives of the patients. This study had been approved by the Ethics Committee of our institution.

\section{Study protocol}

The patients included in the study received midazolam and paralytic agent (vencuronium bromide) before bronchoscopy. The ventilatory parameters were modified before procedure, decreasing peak inspiratory flow, tidal volume, and increasing respiratory rate. During the bronchoscopy, $\mathrm{FI}, \mathrm{O}_{2}$ was administered at $100 \%$. A continuous pulse oximetry (Minolta Pulsox DP-7 Oxygen Saturation Monitor, Japan) and electrocardiographic and pressure monitoring were performed on all patients. Gasometric (arterial blood gases), haemodynamic (cardiac rate, arterial blood pressure), and radiographic controls were performed 6,24 and $48 \mathrm{~h}$ after the procedure.

Before bronchoscopy, a simple blind endotracheal aspiration sample was retrieved using a Lukens device (Moctrap Proclínics, Barcelona, Spain). At the same time, blood cultures were performed on all patients.

\section{Bronchoscopy techniques}

Fibreoptic bronchoscopy using a large channel bronchoscope (Olympus BF 1T-20D; Olympus, New Hyde Park, NY, USA) was performed on all patients. The fibreoptic bronchoscope (FOB) was inserted through the endotracheal or tracheotomy tubes via a sterile connector (Carden Swivel Connector, Bivona, Griffith Microscience Inc, IN, USA) to maintain ventilation during procedure. Suction and injection of lidocaine through the FOB channel were avoided. The FOB was advanced to the chosen bronchial subsegment. The location of sampling was selected on the basis of a chest radiograph or according to the presence of direct inflammatory signs (purulent secretions, mucosal oedema, etc.). PSB and PBAL were always performed in the same subsegmental bronchus.

Protected specimen brush. The tip of the bronchoscope was positioned next to the orifice of the subsegmental bronchus, and the PSB catheter (Microbiology Brush,
Mill-Rose Laboratory Inc., OH, USA) was advanced 3 $\mathrm{cm}$ out of the FOB. The inner cannula was pushed to eject the distal wax plug into a large airway, and the catheter was advanced to the desired subsegment. If purulent secretions were visualized at the subsegmental level, the brush was rotated into them. If secretions were not visualized, the PSB was advanced peripherally until the brush was not visualized without wedging. After sampling, the brush was retracted into the inner cannula and the whole unit was removed from the bronchoscope. The brush was aseptically placed into a sterile tube containing $1.0 \mathrm{~mL}$ of Ringer's lactate solution. Finally, the PSB was immediately delivered to the microbiology laboratory for quantitative bacterial culture.

Protected bronchoalveolar lavage. After PSB, a PB catheter (Protected Bronchoalveolar Lavage Balloon Catheter, Mill-Rose Laboratory Inc., OH, USA) was introduced into the suction channel of the FOB and advanced into the selected subsegment. The balloon was then inflated with $1.5-2 \mathrm{~mL}$ of air to occlude the subsegmental bronchial lumen. The distal plug was then ejected by flushing $2 \mathrm{~mL}$ of sterile saline through the irrigation lumen. PBAL was performed with five $30 \mathrm{~mL}$ aliquots of sterile saline. The material recovered after the first aliquot was discarded. The PBAL effluent was equally divided for bacteriological and cytological analysis.

\section{Microbiological analysis}

The analysis of PSB was carried out as follows: the tube was agitated for $60 \mathrm{~s}$ in a vortex mixer, and using a calibrate loop method, 0.1 and $0.001 \mathrm{~mL}$ of dilution were inoculated into blood, chocolate and MacConkey agars for aerobic cultures and Brucella agar for anaerobic cultures. The analysis of PBAL was similar and a calibrate loop method was used. After straining the BAL sample though sterile gauze to remove mucus, $25 \mu \mathrm{L}$ of sample were mixed with $5 \mathrm{~mL}$ of thioglycollate $(1: 200$ dilution). Twenty five microlitres of the diluted sample $(0.0001 \mathrm{~mL})$ were inoculated into blood, chocolate and MacConkey agars, and incubated at $35^{\circ} \mathrm{C}$ in an atmosphere of $5 \%$ of $\mathrm{CO}_{2}$. All isolates were identified by standard techniques [20]. The susceptibility of micro-organisms was studied using the agar-diffusion method. Positive PSB was defined as bacterial growth $\geq 10^{3}$ colony forming units (cfu) $\cdot \mathrm{mL}^{-1}$ and positive PBAL as $\geq 10^{4} \mathrm{cfu} \cdot \mathrm{mL}^{-1}$. Growth below these values was considered insignificant or negative. To express the total bacterial load of PSB and PBAL, a "bacterial index" (BI) was used as proposed by Johanson et al. [21]. The BI was calculated by converting the bacterial concentration to $\log _{10}$ and adding the values obtained for individual species together.

\section{Cytological analysis}

PBAL samples were also immediately sent to the pathology laboratory, where the sample was strained through a cotton gauze to remove mucus. The specimen was centrifuged at $1,500 \times \mathrm{g}$ for $10 \mathrm{~min}$ (Econospin, Servall Instruments, Du Pont Co., Wilmington, DE, USA). After air-drying the slides, a May-Grünwald Giemsa stain was 
performed. The Giemsa stain preparation was examined under oil-immersion microscope. Three hundred alveolar cells were examined for the presence or absence of ICO. A positive microscopic analysis was defined as the presence of $\geq 2 \%$ of total recovered cells containing ICO. Immediately afterwards, a Gram stain was performed. The result was positive if at least one or more microorganisms were seen in the microscopic examination.

\section{Final diagnosis of cases}

The diagnostic criteria for defining pneumonia was the presence of suggestive clinical and radiological features in combination with positive PSB quantitative cultures and appropriate timing of response to specific antibiotic therapy. Of the initial 102 cases, 35 (34\%) were diagnosed as true pneumonia. Additionally, in 10 of these 35 cases there were other major criteria for diagnosing pneumonia: positive blood culture with the same organisms as found in respiratory secretions in 6 of the 35 $(17 \%)$; rapid cavitation in absence of lung cancer in 2 of the $35(6 \%)$; positive pleural fluid culture in 1 of the $35(3 \%)$; and necropsy in 1 of the $35(3 \%)$.

In the VAP group, 6 out of $35(17 \%)$ cases had received antibiotics after the onset of symptoms suggesting VAP $(<48 \mathrm{~h})$, and another 13 out of $35(37 \%)$ cases were on antibiotics for longer than $48 \mathrm{~h}$ for a prior infection. Only one patient was included in the study more than once; this patient suffered two episodes of VAP separated by several weeks.

A final diagnosis of non-pneumonia was established in 55 of the $102(55 \%)$ cases. In 32 of the $55(58 \%)$ cases, a complete resolution of radiographic infiltrates was observed during the first $48 \mathrm{~h}$ of inclusion, suggesting atelectasis. In 11 of the $55(20 \%)$ cases, adult respiratory distress syndrome (ARDS) was diagnosed according to clinical criteria. In 7 of the $55(13 \%)$ cases, congestive heart failure was demonstrated by haemodynamic measurements. Pleural effusion of noninfectious origin was diagnosed in 3 of the $55(5 \%)$ cases, one case $(2 \%)$ had tuberculosis, and, finally, one case $(2 \%)$ had empyema secondary to an abdominal abscess. In only six of the 55 cases where pneumonia had been finally excluded were the patients not receiving antibiotic treatment. The other 49 patients were already on antibiotics, for less than $48 \mathrm{~h}$ in 11 out of $49(22 \%)$ cases, and for a longer period of time $(>48 \mathrm{~h})$ in 38 out of $49(77 \%)$. Finally, in 12 of the $102(12 \%)$ cases, there was disagreement among the authors about the presence or absence of pneumonia and these cases were considered indeterminate, and therefore excluded from further calculations.

\section{Statistical analysis}

Results are expressed as mean \pm standard deviation (SD). The final diagnosis of cases - true pneumonia or nonpneumonia - was used as the standard for establishing the diagnostic efficacy of PBAL. This was expressed as sensitivity, specificity, and positive predictive value (PPV) and negative predictive value (NPV). Comparisons between groups of patients were made using the Mann-Whitney
U-test for variables with no normal distribution. Comparisons between values measured in the same patients were made using Wilcoxon rank sum test. P-values of less than 0.05 were considered to be statistically significant.

\section{Results}

During the study period, 102 episodes of suspected ventilator-associated pneumonia (VAP) were evaluated in 93 patients. The general characteristics of this population are presented in table 1. The average volume of PBAL fluid retrieved was $37.4 \pm 18.9 \mathrm{~mL}$ (range $10-115 \mathrm{~mL}$ ). The cytological analysis of PBAL is summarized in table 2.

\section{Bacteriological results}

VAP Group. The microbiological results of PBAL in the 35 cases with VAP are summarized in tables 3-5, divided into three subgroups. PBAL quantitative cultures were positive in 30 out of $35(86 \%)$ cases of confirmed

Table 1. - Clinical characteristics of patients at time of entry into the study

\begin{tabular}{ll}
\hline Patients $\mathrm{n}$ & 93 \\
Episodes of suspected VAP $\mathrm{n}$ & 102 \\
Sex M/F & $75 / 18$ \\
Mean age yrs & $45 \pm 20$ \\
Indication for ventilatory support & \\
$\quad$ Postsurgical status & 37 \\
Trauma patients & 40 \\
$\quad$ Head trauma & 24 \\
$\quad$ Multiple trauma & 16 \\
Medical problems & 16 \\
$\quad$ Neurological disorders & 5 \\
$\quad$ Cardiac insufficiency & 5 \\
$\quad$ Pancreatitis & 4 \\
$\quad$ Community acquired pneumonia & 2 \\
Duration of mechanical ventilation days & $11.3 \pm 10$ \\
Surgical operation before VAP days & $6.7 \pm 9.8$ \\
Prior antibiotics & $79 / 102(77)$ \\
Radiological patterns & \\
Unilateral alveolar infiltrates & $75 / 102(73)$ \\
Bilateral alveolar infiltrates & $27 / 102(26)$ \\
Bilateral interstitial pattern & $1 / 102(1)$ \\
\hline
\end{tabular}

Values in parenthesis are percentages. M: male; F: female; VAP: ventilator-associated pneumonia.

Table 2. - PBAL cytological characteristics

\begin{tabular}{lccc}
\hline & $\begin{array}{c}\text { VAP } \\
(\mathrm{n}=35)\end{array}$ & $\begin{array}{c}\text { Non-VAP } \\
(\mathrm{n}=55)\end{array}$ & $\mathrm{p}$-value \\
\hline $\begin{array}{c}\text { Total alveolar cells } \\
\text { cells·mm }\end{array}$ & & & \\
Macrophages \% & $2989 \pm 2789$ & $1193 \pm 1258$ & 0.0003 \\
Neutrophils \% & $17 \pm 23$ & $32 \pm 29$ & 0.002 \\
Eosinophils \% & $73 \pm 31$ & $63 \pm 30$ & 0.01 \\
Lymphocytes \% & $1 \pm 6$ & $0.4 \pm 3$ & NS \\
SEC \% & $2 \pm 3$ & $2 \pm 3$ & NS \\
ICO \% & $0.3 \pm 1$ & $0.6 \pm 2$ & NS \\
\hline
\end{tabular}

Values are presented as mean \pm SD. SEC: squamous epithelial cells; ICO: intracellular organisms; PBAL: protected bronchoalveolar lavage; VAP: ventilator-associated pneumonia; NS: nonsignificant. 
Table 3. - Microbiological and cytological results in patients with pneumonia and no prior antibiotics

\begin{tabular}{|c|c|c|c|c|c|}
\hline $\begin{array}{l}\mathrm{Pt} \\
\text { No. }\end{array}$ & Micro-organisms & $\begin{array}{c}\text { PSB } \\
\mathrm{cfu} \cdot \mathrm{mL}^{-1}\end{array}$ & $\begin{array}{c}\mathrm{PBAL} \\
\mathrm{cfu} \cdot \mathrm{mL}^{-1}\end{array}$ & $\begin{array}{c}\mathrm{ICO} \\
\%\end{array}$ & Gram \\
\hline \multirow[t]{2}{*}{1} & S. aureus & $1.0 \times 10^{5}$ & $1.0 \times 10^{5}$ & & \\
\hline & A. anitratus & - & $8.0 \times 10^{4}$ & 15 & GPC \\
\hline \multirow[t]{3}{*}{2} & S. pneumoniae & $1.0 \times 10^{5}$ & $1.0 \times 10^{5}$ & & \\
\hline & P. multocida & $1.0 \times 10^{5}$ & $1.0 \times 10^{5}$ & & \\
\hline & E. aerogenes & $5.0 \times 10^{3}$ & $1.0 \times 10^{4}$ & 10 & GPC \\
\hline 3 & S. aureus & $1.0 \times 10^{4}$ & $2.0 \times 10^{4}$ & 9 & GPC \\
\hline 4 & S. aureus & $1.0 \times 10^{5}$ & $1.0 \times 10^{5}$ & 9 & GPC \\
\hline \multirow[t]{2}{*}{5} & S. pneumoniae & $1.0 \times 10^{5}$ & $1.0 \times 10^{5}$ & & \\
\hline & H. Influenzae & $1.0 \times 10^{5}$ & $1.0 \times 10^{6}$ & 10 & GPC \\
\hline 6 & M. catarrhalis & $1.0 \times 10^{4}$ & $1.0 \times 10^{5}$ & 8 & GNDC \\
\hline 7 & P. aeruginosa & $5.0 \times 10^{3}$ & $5.0 \times 10^{5}$ & 2 & - \\
\hline 8 & P. aeruginosa & $1.0 \times 10^{4}$ & $2.0 \times 10^{4}$ & 0 & - \\
\hline 9 & S. pneumoniae & $1.0 \times 10^{5}$ & $1.0 \times 10^{5}$ & 15 & GPC \\
\hline 10 & H. influenzae & $1.0 \times 10^{5}$ & $1.0 \times 10^{6}$ & 11 & GNCB \\
\hline \multirow[t]{4}{*}{11} & Citrobacter spp. & $1.0 \times 10^{4}$ & $1.0 \times 10^{4}$ & & GNB \\
\hline & S. epidermidis & $2.0 \times 10^{3}$ & $3.0 \times 10^{3}$ & & GPC \\
\hline & S. anginosus & $3.0 \times 10^{4}$ & $3.5 \times 10^{4}$ & & \\
\hline & Corynebacterium spp. & $3.0 \times 10^{4}$ & $4.0 \times 10^{4}$ & 7 & \\
\hline \multirow[t]{2}{*}{12} & S. aureus & $1.5 \times 10^{4}$ & $8.0 \times 10^{3}$ & & \\
\hline & H. influenzae & $2.0 \times 10^{3}$ & - & 2 & GN \\
\hline 13 & H. influenzae & $6.0 \times 10^{4}$ & $5.0 \times 10^{4}$ & 2 & GNCB \\
\hline \multirow[t]{2}{*}{14} & H. influenzae & $1.0 \times 10^{5}$ & $1.0 \times 10^{6}$ & & GNCB \\
\hline & S. aureus & $1.0 \times 10^{4}$ & $1.0 \times 10^{5}$ & 20 & GNCB \\
\hline \multirow[t]{3}{*}{15} & S. pneumoniae & $1.0 \times 10^{5}$ & $3.0 \times 10^{5}$ & 20 & GPC \\
\hline & S. aureus & $1.0 \times 10^{5}$ & $1.0 \times 10^{5}$ & & GPC \\
\hline & P. mirabilis & $7.0 \times 10^{3}$ & - & 8 & GNB \\
\hline \multirow[t]{4}{*}{16} & A. anitratus & $1.0 \times 10^{5}$ & $1.0 \times 10^{4}$ & & \\
\hline & S. pneumoniae & $2.5 \times 10^{4}$ & $1.5 \times 10^{4}$ & & \\
\hline & H. influenzae & $1.5 \times 10^{4}$ & $1.0 \times 10^{6}$ & & \\
\hline & P. vulgaris & $5.0 \times 10^{4}$ & $4.0 \times 10^{3}$ & 50 & - \\
\hline
\end{tabular}

Pt: patient; PSB: protected specimen brush; cfu: colony-forming units; PBAL: protected bronchoalveolar lavage; ICO: intracellular organisms; GPC: Gram-positive cocci; GNDC: Gram-negative diplococci; GNCB: Gram-negative coccobacilli; GNB: Gram-negative bacilli; GN: Gram-negative,

Table 4. - Microbiological and cytological results in patients with pneumonia on antibiotic treatment for less than $48 \mathrm{~h}$

\begin{tabular}{llcccc}
\hline $\begin{array}{l}\text { Pt } \\
\text { No. }\end{array}$ & $\begin{array}{l}\text { Micro- } \\
\text { organisms }\end{array}$ & $\begin{array}{c}\text { PSB } \\
\mathrm{cfu} \cdot \mathrm{mL}^{-1}\end{array}$ & $\begin{array}{c}\mathrm{PBAL} \\
\mathrm{cfu} \cdot \mathrm{mL}^{-1}\end{array}$ & $\begin{array}{c}\text { ICO } \\
\%\end{array}$ & Gram \\
\hline 1. & S. aureus & $1.0 \times 10^{5}$ & $5.0 \times 10^{4}$ & & \\
& A. anitratus & $4.0 \times 10^{3}$ & - & 3 & GNB \\
2 & H. influenzae & $1.0 \times 10^{5}$ & $2.0 \times 10^{4}$ & 4 & GNCB \\
3 & S. sanguis & $1.0 \times 10^{4}$ & $8.0 \times 10^{4}$ & 5 & GPC \\
4 & E. aerogenes & $1.0 \times 10^{3}$ & $1.0 \times 10^{6}$ & - & - \\
5 & S. aureus & $1.0 \times 10^{3}$ & $1.6 \times 10^{5}$ & 3 & GPC \\
6 & S. aureus & $5.0 \times 10^{3}$ & $8.0 \times 10^{3}$ & & \\
& A. anitratus & $1.0 \times 10^{5}$ & $6.4 \times 10^{4}$ & 0 & - \\
\hline
\end{tabular}

For definitions see legend to table 3 .

VAP. In the other 5 out of $35(14 \%)$ cases the growth was lower than $10^{4} \mathrm{cfu} \cdot \mathrm{mL}^{-1}$, and they were considered as false negative results. There was a complete agreement (same isolated organisms) between PSB and PBAL in 30 of the $35(86 \%)$ episodes of VAP and partial agreement (at least one common organism in both techniques) in 5 of the $35(14 \%)$. Polymicrobial growth was observed in 13 of the $35(37 \%)$ cases.
Table 5. - Microbiological and cytological results in patients with pneumonia on antibiotic for more than $48 \mathrm{~h}$

\begin{tabular}{clcccc}
\hline $\begin{array}{l}\mathrm{Pt} \\
\text { No. }\end{array}$ & Micro-organisms & $\begin{array}{c}\mathrm{PSB} \\
\mathrm{cfu} \cdot \mathrm{mL}^{-1}\end{array}$ & $\begin{array}{c}\mathrm{PBAL} \\
\mathrm{cfu} \cdot \mathrm{mL}^{-1}\end{array}$ & $\begin{array}{c}\text { ICO } \\
\%\end{array}$ & Gram \\
\hline 1 & P. aeruginosa & $1.0 \times 10^{4}$ & $1.0 \times 10^{3}$ & & \\
& A. anitratus & - & $1.0 \times 10^{5}$ & 0 & - \\
2 & P. aeruginosa & $1.0 \times 10^{5}$ & $1.0 \times 10^{3}$ & 0 & - \\
3 & A. anitratus & $5.0 \times 10^{4}$ & $2.0 \times 10^{3}$ & 0 & - \\
4 & K. pneumoniae & $1.0 \times 10^{5}$ & $1.0 \times 10^{5}$ & & \\
& S. aureus & $2.0 \times 10^{4}$ & $3.0 \times 10^{4}$ & & \\
& MRSA & $1.0 \times 10^{5}$ & $1.0 \times 10^{5}$ & 5 & GPC \\
5 & A. anitratus & $1.0 \times 10^{5}$ & $2.0 \times 10^{3}$ & 0 & - \\
6 & P. maltophila & $1.0 \times 10^{4}$ & $1.0 \times 10^{5}$ & - & - \\
7 & C. albicans & $1.0 \times 10^{3}$ & $1.0 \times 10^{4}$ & & \\
& S. sanguis & $1.0 \times 10^{6}$ & $1.0 \times 10^{6}$ & 0 & GPC \\
8 & P. aeruginosa & $1.0 \times 10^{5}$ & $1.0 \times 10^{5}$ & 1 & GNB \\
9 & S. aureus & $3.0 \times 10^{4}$ & $5.0 \times 10^{4}$ & 5 & GPC \\
10 & S. aureus & $6.0 \times 10^{3}$ & $8.0 \times 10^{3}$ & 4 & GPC \\
11 & P. aeruginosa & $3.0 \times 10^{4}$ & $1.0 \times 10^{5}$ & - & - \\
12 & P. aeruginosa & $1.0 \times 10^{5}$ & $5.0 \times 10^{4}$ & & GNB \\
& S. pneumoniae & $2.0 \times 10^{4}$ & $1.0 \times 10^{5}$ & 4 & GPC \\
13 & S. aureus & $2.0 \times 10^{4}$ & $2.4 \times 10^{4}$ & & GPC \\
& A. anitratus & $2.5 \times 10^{4}$ & $8.0 \times 10^{3}$ & 4 & GNB \\
\hline
\end{tabular}

MRSA: methicillin resistant Staphylococcus aureus. For further definitions see legend to table 3 .

Non-VAP group. PBAL was negative in 50 out of 55 $(91 \%)$ cases. False positive results were obtained in 5 out of $55(9 \%)$ cases.

\section{Cytological results}

VAP Group. A Giemsa stain of PBAL samples was performed in 32 of the 35 cases of VAP. The PBAL cytological characteristics in patients with and without pneumonia are shown in table 2 . ICO, at a level $\geq 2 \%$ of the retrieved alveolar cells, were seen in 24 of the $32(75 \%)$ cases. In 8 of the $32(25 \%)$ cases a false negative result was observed, and seven of these were already receiving antibiotics. A Gram stain of the PBAL sample was carried out in 24 of the $35(69 \%)$ cases and was positive in 23 of the $24(96 \%)$ : Gram-positive cocci were seen in 13 patients; Gram-negative bacilli in two; Gramnegative coccobacilli in three; and polymicrobial flora in five.

Non-VAP group. A Giemsa stain of PBAL was performed in all of the 55 patients with non-VAP. More than 2\% of ICO was observed in 1 of the $55(2 \%)$ patients. The final diagnosis in this case was atelectasis.

A Gram stain of PBAL was performed in 19 of the $55(35 \%)$ cases. The results obtained were positive in 5 out of 19 (26\%) cases: Gram-positive cocci in 3 out of $19(16 \%)$ cases (one with negative PBAL culture); Gram-positive bacilli in 1 out of 19 (negative PBAL culture); and Gram-negative bacilli in 1 out of 19 .

\section{Diagnostic efficacy of PBAL}

The efficacy of PBAL in diagnosing pneumonia in ventilated patients is shown in table 6 . The sensitivity 
Table 6. - Diagnostic efficacy of PBAL

\begin{tabular}{lcccc}
\hline & $\begin{array}{c}\text { Sensitivity } \\
\%\end{array}$ & $\begin{array}{c}\text { Specificity } \\
\%\end{array}$ & $\begin{array}{c}\text { PPV } \\
\%\end{array}$ & $\begin{array}{c}\text { NPV } \\
\%\end{array}$ \\
\hline $\begin{array}{l}\text { Quantitative } \\
\text { cultures }\end{array}$ & 87 & 91 & 87 & 91 \\
ICO & 75 & 98 & 96 & 86 \\
\hline
\end{tabular}

PBAL: protected bronchoalveolar lavage; ICO: intracellular organisms; PPV: positive predictive value; NPV: negative predictive value.

of ICO was lower than that of PBAL quantitative cultures. However, its specificity was higher than that of PBAL cultures.

\section{Effect of antibiotic therapy on microbiological and cyto- logical results}

PBAL cultures. As shown in figure 1, the mean BI of PBAL in patients who did not receive antibiotics $(8.3 \pm 4.36)$ was higher than the BI of patients with antibiotics $(<48$ or $>48 \mathrm{~h}$ ), although the differences were not significant. The mean BI of patients who had recently received antibiotics $(<48 \mathrm{~h})$ was $5.6 \pm 1.59$, slightly lower than the $\mathrm{BI}$ in patients who had received antibiotics for a long period of time $(>48 \mathrm{~h})(6.1 \pm 3.18)$, although the differences between these two groups were not significant $(p=0.65)$. Likewise, no significant differences between these two groups were observed in terms of bacterial concentration (fig. 2). In patients in whom the anti-microbial treatment was present for a long period of time ( $>48$ $\mathrm{h})$, the micro-organisms isolated were resistant to previous antibiotics (table 5).

Cytological analysis. The mean percentage of alveolar cells with ICO in patients with VAP and no prior antibiotics $(11.3 \pm 11.7 \%)$ was significantly higher than the mean value of ICO in patients who did receive antibiotics $<48 \mathrm{~h}(2.5 \pm 2 \%)(\mathrm{p} \leq 0.01)$ and $>48 \mathrm{~h}(2.15 \pm 3 \%)$ $(\mathrm{p}=0.009)$. The mean percentage of alveolar cells with ICO in patients who had received antibiotics for less than $48 \mathrm{~h}$ was higher than that of patients on antibiotics for more than $48 \mathrm{~h}$, although the difference was not significant (fig. 3).

\section{Complications of bronchoscopy}

In seven cases $(7 \%)$ an oxygen desaturation (below $\leq 90 \%$ ) was observed during the procedure. In four cases (4\%), minor bronchial bleeding was observed after bronchoscopy. A pneumothorax that needed pleural drainage was detected in one case $(1 \%)$. No arrhythmias or haemodynamic instability were observed in these cases.

\section{Discussion}

In this study, we evaluated the diagnostic efficacy of PBAL in a group of VAPs, diagnosed according to the classical criteria plus a positive PSB. Both the quantitative cultures of PBAL and the cytological examination

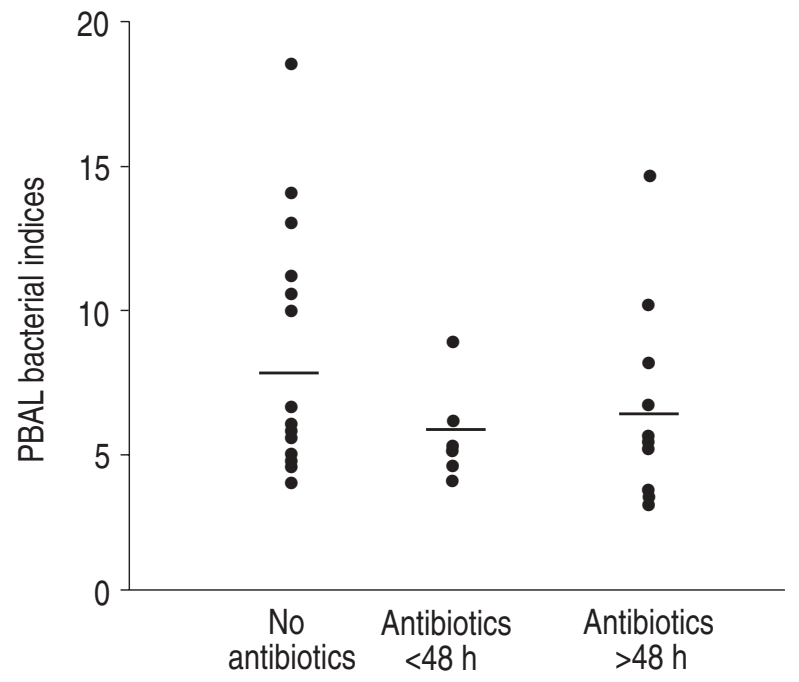

Fig. 1. - Individual (solid circles) and mean bacterial indices of PBAL in patients with VAP in the three different groups depending on the use of antibiotics. No significant differences were observed between the three groups. PBAL: protected bronchoalveolar lavage; VAP: ventilator-associated pneumonia.

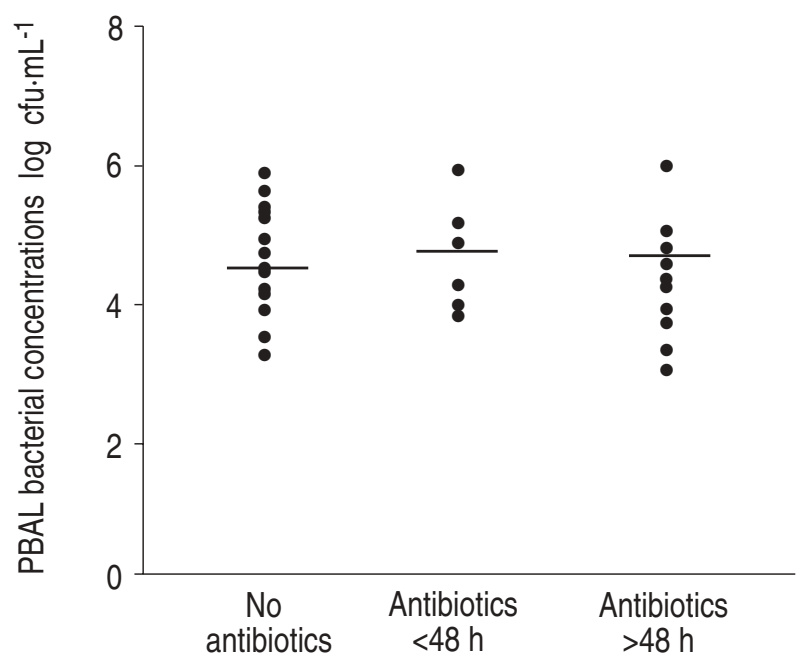

Fig. 2. - Individual bacterial concentrations (solid circles) of PBAL in patients with VAP in the three different groups depending on the antibiotic use. Horizontal bars indicate means. No significant differences were observed between the groups. cfu: colony-forming units. For further definitions see legend to figure 1.

offered a good diagnostic efficacy, confirming the results obtained by MeduRI and co-workers [18, 19]. There are some inherent limitations in evaluating the diagnostic efficacy of a technique such as PBAL in a clinical model, characterized by the lack of a gold standard in a significant percentage of cases. Considering only the diagnostic efficacy, animal or cadaveric models can provide excellent gold standards. However, key issues, such as safety or the influence of prior antibiotics, can be better analysed in a real clinical setting.

\section{PBAL procedure}

The average material recovered by conventional BAL is variable [13], and it is believed to contain at least $1 \mathrm{~mL}$ 


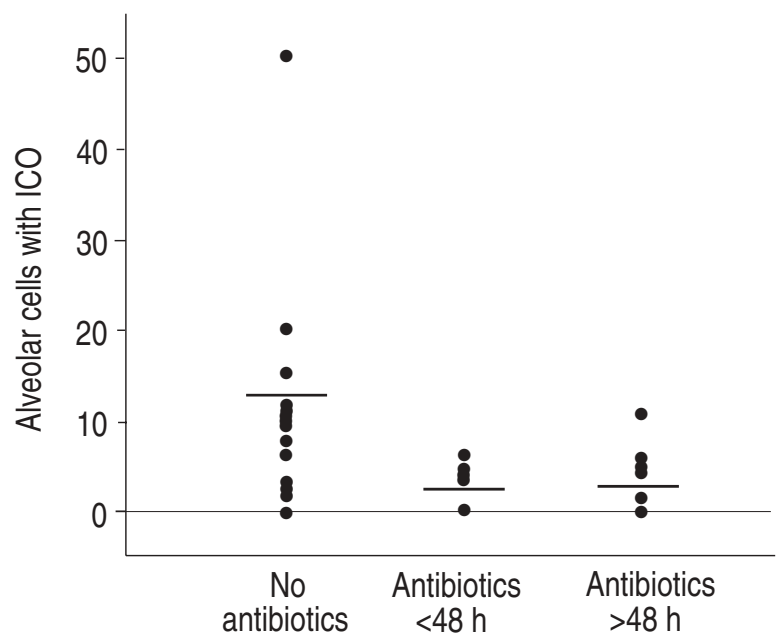

Fig. 3. - Individual (solid circles) and mean percentage of alveolar cells with ICO in VAP group depending on previous antibiotic therapy. For definitions see legend o figure 1.

of undiluted respiratory secretions. Most of published series dealing with BAL in the diagnosis of pneumonia do not provide any specific data concerning the percentage of recovered fluid. On the other hand, our figure $(25 \%)$ is comparable, or even higher, than that obtained by other authors [22]. The use of a protected-balloon catheter has two potential advantages: to reduce the risk of contamination during the procedure, and to recover a larger amount of valid material. In our study, the average volume of valid PBAL recovered material was $37.4 \pm 18.9 \mathrm{~mL}(25 \%)$. However, because of the small lumen of the protected-balloon catheter, there is a potential risk of obstruction by bronchial secretions and, in that case, the recovered sample may be substantially smaller. In our experience, this occurred in only four cases $(4 \%)$

\section{PBAL quantitative cultures}

A substantial number of investigations have revealed a polymicrobial growth in VAP patients $[9,23]$, and these results do not suggest bacterial contamination. Several studies have suggested that quantitative cultures of BAL may be useful in the aetiological diagnosis of pneumonia. In a group of 57 nonventilated patients undergoing bronchoscopy, KHAN and JONES [17] found bacterial isolates above the cut-off point of $10^{5}$ in 13 patients with pneumonia and in three patients with acute bronchitis. No false negative results were found. THORPE et al. [16] analysed quantitative cultures of BAL in 92 nonventilated patients. Thirteen out of 15 patients with pneumonia presented BAL culture $\geq 10^{5} \mathrm{cfu} \cdot \mathrm{mL}^{-1}(86 \%$ sensitivity), whereas 4 of $58(7 \%)$ patients without pneumonia presented a positive culture. In a group of 18 ventilated patients with VAP, GUERRA et al. [15] found false negative results in $11 \%$ of cases. CHASTRE and co-workers [13] concluded that cultures of BAL fluid were not useful in diagnosing VAP. This study found $20 \%$ false negative BAL results and $30 \%$ false positive ones. Nevertheless, more recently [24], this group has also compared the results of PSB and unprotected BAL versus histology and quantitative lung cultures in a cadaveric model. The sensitivity and specificity of BAL cultures were $100 \%$ and $88 \%$. In a group of 27 ventilated patients without VAP, TORRES et al. [22] showed a considerable percentage of false positive results of BAL quantitative cultures. A high percentage of false positive results $(18 \%)$ has been identified by other authors [25]. Globally, false positive results were associated with a high degree of contamination of BAL samples, and false negative results in these studies could be associated with the use of previous antibiotics.

CASTELla et al. [26] compared protected BAL performed through a protected telescoping catheter with conventional BAL and PSB in 41 patients with pneumonia and 16 control patients. The diagnostic sensitivity and specificity of each technique were 85 and $83 \%$, respectively, for protected BAL, 82 and $44 \%$ for BAL, and 62 and $96 \%$ for PSB.

The introduction of a protected-balloon catheter to perform the BAL could reduce the false positive results. MEDURI and co-workers [18] found neither false positive nor false negative results using this device. In a group of 25 ventilated patients without antibiotics for $\geq 48 \mathrm{~h}$ with suspected VAP, the sensitivity and specificity were $100 \%$. In our study only 5 out of $35(14 \%)$ cases of confirmed VAP bacterial growth $<10^{4} \mathrm{cfu} \cdot \mathrm{mL}^{-1}$ (87\% sensitivity), four of them were on antibiotics. In the non-VAP group, only 5 out of $55(9 \%)$ positive results of BAL were observed ( $91 \%$ specificity), all of them with prior antibiotics.

\section{Cytological examination}

The number of inflammatory cells in the BAL fluid correlated poorly with the presence of pneumonia, as has been reported by CHASTRE and co-workers [13]. Other laboratory parameters, such as differential blood leucocyte counts or C-reactive protein, are of limited value in this setting.

Quantification of ICO proved to be very useful in diagnosing VAP. In our study, we used a cut-off point of $2 \%$ according to the figure suggested by MEDURI and co-workers $[18,19]$. CHASTRE and co-workers initially suggested a cut-off point of $25 \%$ [13], but later these authors proposed $7 \%$ [14], and more recently an even lower cutoff of 5\%. In a study performed by CHASTRE and co-workers [13], BAL samples were Giemsa stained in 21 cases. Those cases with confirmed VAP showed a high percentage of $\operatorname{ICO}(>25 \%)$. By contrast, less than $1 \%$ of ICO were observed in 9 out of 13 patients without pneumonia. The same authors [14] later compared BAL and PSB in a large series of 61 patients with suspected nosocomial pneumonia. Accepting a cut-off point of ICO $\geq 7 \%$, only two false negative and two false positive results were observed ( $86 \%$ sensitivity and $96 \%$ specificity). More recently, MEDURI and co-workers [19] found similar results with Giemsa and Gram stains of PBAL. The methodology of this study was somewhat different. Firstly, BAL was performed with a protected-balloon catheter to avoid contamination, and secondly, a different cut-off for ICO ( $\geq 2 \%)$ was considered. In 13 patients with pneumonia, ICO at $\geq 2 \%$ were found in 8 out of 10 ( $80 \%$ sensitivity). In this study, no false positive results for ICO were observed. 
In our series, with the same methodology as used by MEDURI and co-workers [18], 8 out of $32(25 \%)$ samples in the VAP group were negative for ICO $(75 \%$ sensitivity). In the non-VAP group, only one ICO false positive result was observed ( $98 \%$ specificity).

\section{Influence of prior antibiotics in PBAL results}

The diagnostic value of PSB or PBAL could be modified by the use of previous antibiotics $[14,21]$. Recently, two groups [27, 28] have demonstrated that causative pathogens isolated from PSB can be rapidly eradicated by antibiotic therapy. Meduri and co-workers [19], found a decrease in the bacterial load of PBAL and PSB in patients with prior antibiotics. The mean concentration of PSB was affected more than that of PBAL. We agree that owing to the potential effect of prior antibiotics on PSB results, when the patients are already treated, it is difficult to rule out pneumonia based exclusively on a negative PSB result.

In our series, however, in the group of patients considered as not having pneumonia, there was evidence other than a negative PSB that contributed to discounting pneumonia. Among the 11 cases without VAP and treated for less than $48 \mathrm{~h}$, an alternative diagnosis of atelectasis was obtained in all cases. In 38 out of 55 cases treated for a longer period of time, the alternative diagnoses were: atelectasis in 21 cases; congestive heat failure in seven; ARDS in five; pleural effusion in three; tuberculosis in one; and empyema in one. It is also important to note that in a significant percentage of our patients, the antibiotics prior prescribed to the diagnosis of pneumonia would have little activity against potential respiratory pathogens. On the other hand, as we have recently described [29], the effect of prior antibiotics on the yield of cultures is much more evident in the case of streptococcal and $H$. influenzae respiratory infections rather than Gram-negative bacilli, which are much more frequent in VAP.

There were two distinct conditions among the patients on antibiotics before the application of sampling techniques. One was the case of patients who had received antibiotics for a long period of time ( $>48 \mathrm{~h}$ ) because of a previous episode of infection, respiratory or not, before the appearance of a new pulmonary infiltrate. In this setting, the microorganisms isolated were resistant to the previous antibiotics. A second situation was the case where antibiotics were started shortly before $(<48 \mathrm{~h})$ the application of the technique studied. Therefore, we separated the cases into each of these conditions. However, as shown in figures 1 and 2 , the mean BI and the bacterial concentrations of PBAL were not significantly different between these two groups. The mean percentage of alveolar cells with ICO in patients with confirmed VAP and no prior antibiotics was $11.3 \pm 11.6 \%$. This mean value was significantly higher when compared with those obtained in either group with previous antibiotics $(<48$ h or $>48$ h) (fig. 3).

ICO were not found in 6 out of 11 cases, diagnosed as true pneumonias and already on antibiotics for a long period of time $(>48 \mathrm{~h})$, whilst quantitative PBAL and PSB cultures were positive. This event raises the possibility that PSB and PBAL cultures could in fact be false positive results. Nevertheless, in two of these six cases the diagnosis of pneumonia was also supported by a positive blood culture (with the bacterial isolate also found in the respiratory secretions), pleural fluid culture was positive in another, there was rapid cavitation (also a major criterion) in another, and, finally, there was necropsic evidence of pneumonia in the last one. Therefore, in 5 of these 6 cases where ICO were not found whilst quantitative PSB and PBAL cultures were positive, there was strong evidence for diagnosing pneumonia. Thus, these cases have to be considered as false negative results of the ICO technique.

There are few studies which have evaluated the effect of antibiotics on recovered ICO. To determine the effect of prior antibiotics on ICO, Dotson and Pingleton [30] evaluated 49 episodes of suspected VAP. In patients receiving antibiotic therapy at the time of sampling, ICO were found in only $6 \%$ of cases; whereas, in the group of cases without previous antibiotics, ICO were found in $54 \%$. The mean percentage of ICO was higher in patients who were not receiving antibiotics. Our results agree with those obtained by Dotson and Pingleton [30], and permit the conclusion that ICO examination is rapidly affected by antibiotics.

\section{PBAL potential utility}

The bronchoscopic PSB technique has been extensively studied in clinical, cadaveric and animal models offering a good sensitivity and specificity. Nevertheless, PSB has three major drawbacks. Firstly, by accepting a cutoff point of $10^{3} \mathrm{cfu} \cdot \mathrm{mL}^{-1}$ for separating colonization from infection, a few false positive results may be observed. Secondly, the results of cultures require $24-48 \mathrm{~h}$. Finally, negative results have been observed, especially in patients with previous antibiotics. To overcome these problems, several approaches based on BAL have been developed. The use of PBAL could have potential advantages: firstly, it permits a rapid cytological analysis to detect intracellular bacteria in alveolar cells; secondly, PBAL cultures seem to be less affected by a prior antibiotic treatment than PSB [19]; and finally, the lavage may also be useful for the diagnosis of other forms of respiratory failure in ventilated patients, such as pulmonary haemorrhage or nonbacterial infections.

It is probable that protected bronchoalveolar lavage could be a valid alternative to the combination of protected specimen brush plus bronchoalveolar lavage suggested by some authors [31].

Acknowledgements: The authors wish to thank R. Brossa and A. Funes, cytologists of the International Academy of Cytology, for expert technical assistance in the cytological examination of samples.

\section{References}

1. Andrews CP, Coalson JJ, Smith JD, Johanson WG. Diagnosis of nosocomial pneumonia in acute diffuse lung injury. Chest 1981; 80: 254-258.

2. Fagon JY, Chastre J, Hance AJ, et al. Detection of nosocomial lung infection in ventilated patients: use of a protected specimen brush and quantitative culture technique in 147 patients. Am Rev Respir Dis 1988; 138: 110-116. 
3. Meduri GU. Ventilator-associated pneumonia in patients with respiratory failure: a diagnostic approach. Chest 1990; 97: 1208-1219.

4. Johanson WG, Pierce AK, Sanford JP, Thomas GD. Nosocomial respiratory infection with Gram-negative bacilli: the significance of colonization of respiratory tract. Ann Intern Med 1972; 77: 701-708.

5. Wimberley N, Faling LJ, Barlett JG. A fiberoptic bronchoscopy technique to obtain uncontaminated lower airway secretions for bacterial culture. Am Rev Respir Dis 1979; 130: 924-929.

6. Villers D, Derriennic M, Raffi F, et al. Reliability of the bronchoscopic protected catheter brush in intubated and ventilated patients. Chest 1985; 88: 527-529.

7. Baughman RP, Thorpe JE, Staneck J, Rashkin M, Frame PT. Use of the protected specimen brush in patients with endotracheal or tracheostomy tubes. Chest 1988; 93 : 746-750.

8. Chastre J, Viau F, Brun P, et al. Prospective evaluation of the protected specimen brush for the diagnosis of pulmonary infections in ventilated patients. Am Rev Respir Dis 1984; 130: 924-929.

9. Fagon JY, Chastre J, Domart Y, et al. Nosocomial pneumonia in patients receiving continuous mechanical ventilation. Prospective analysis of 52 episodes with use of a protected specimen brush and quantitative culture techniques. Am Rev Respir Dis 1989; 139: 877-884.

10. Torres A, Puig de la Bellacasa J, Rodriguez-Roisin R, Jimenez de Anta MT, Agustí Vidal A. Diagnostic value of telescoping plugged catheters in mechanically-ventilated patients with bacterial pneumonia using the metras catheter. Am Rev Respir Dis 1988; 138: 117-120.

11. Pham L HA, Brun-Buisson C, Legrand P, et al. Diagnosis of nosocomial pneumonia in mechanically-ventilated patients: comparison of a plugged telescoping catheter with the protected specimen brush. Am Rev Respir Dis 1991; 143: 1055-1061.

12. Wimberley NW, Bass JB, Boyd BW, Kirkpatrick MB, Seno RA, Pollock HM. Use of a bronchoscopic protected catheter brush for the diagnosis of pulmonary infections. Chest 1982; 81: 556-562.

13. Chastre J, Fagon JY, Soler P, et al. Diagnosis of nosocomial bacterial pneumonia in intubated patients undergoing ventilation: comparison of the usefulness of bronchoalveolar lavage and the protected specimen brush. Am J Med 1988; 85: 499-506.

14. Chastre J, Fagon JY, Soler P, Domart Y. Quantification of BAL cells containing intracellular bacteria rapidly identifies ventilated patients with nosocomial pneumonia. Chest 1989; 85: 190-192S.

15. Guerra LF, Baughman RP. Use of bronchoalveolar lavage to diagnose bacterial pneumonia in mechanically ventilated patients. Crit Care Med 1990; 18: 169-173.

16. Thorpe J, Baughman RP, Frame P, Wessler T. Bronchoalveolar lavage for diagnosing acute bacterial pneumonia. J Infect Dis 1987; 155: 855-861.
17. Kahn F, Jones J. Diagnosing bacterial respiratory infection by bronchoalveolar lavage. J Infect Dis 1987; 155: 862-869.

18. Meduri GU, Wunderink RG, Leeper KW, Beals DH. Management of bacterial pneumonia in ventilated patients: protected bronchoalveolar lavage as a diagnostic tool. Chest 1992; 101: 500-508.

19. Meduri GU, Beals D, Maijub G, Baselski V. Protected bronchoalveolar lavage: a new bronchoscopic technique to retrieve uncontaminated distal airway secretions. Am Rev Respir Dis 1991; 143: 855-864.

20. Lennette EH, Balows A, Hanoler WJ Jr, Shadomy HJ, eds. Manual of Clinical Microbiology. 4th edn. Washington DC, American Society of Microbiology, 1985.

21. Johanson WG, Seidenfeld J, Gomez P, De los Santos R, Coalson JJ. Bacteriologic diagnosis of nosocomial pneumonia following prolonged mechanical ventilation. Am Rev Respir Dis 1988; 137: 259-264.

22. Torres A, Martos A, Puig de la Bellacasa J, et al. Specificity of endotracheal aspiration, protected specimen brush and bronchoalveolar lavage in mechanically-ventilated patients. Am Rev Respir Dis 1993; 147: 952-957.

23. Rello J, Quintana E, Ausina V, et al. Incidence, etiology, and outcome of nosocomial pneumonia in mechanically-ventilated patients. Chest 1991; 100: 439-444.

24. Chastre J, Fagon JY, Bornet M, et al. Comparison of the usefulness of bronchoalveolar lavage and the protected specimen brush for diagnosing nosocomial bacterial pneumonia. Am Rev Respir Dis 1992; 145: A542.

25. Rodriguez de Castro F, Solé J, Elcuaz R. Quantitative cultures of protected brush specimens and bronchoalveolar lavage in ventilated patients without suspected pneumonia. Am J Respir Crit Care Med 1994; 149: 320-323.

26. Castella J, Puzo C, Ausina V, et al. Diagnosis of pneumonia with a method of protected bronchoalveolar lavage. Eur Respir J 1991; 4: 407S.

27. Blavia R, Dorca J, Verdaguer R, Carratalá J, Gudiol F, Manresa F. Bacteriological follow-up of nosocomial pneumonia by successive protected specimen brush. Eur Respir J 1991; 4 (Suppl.): 407S.

28. Montravers P, Fagon JY, Chastre J, et al. Follow-up protected specimen brushes to assess treatment in nosocomial pneumonia. Am Rev Respir Dis 1993; 147: 38-44.

29. Prats E, Dorca J, Irigaray R, et al. Bacteriological follow-up of ventilator-associated pneumonia during the first 24 hours of antibiotic treatment. Am J Respir Crit Care Med 1995; 151: A791.

30. Dotson RG, Pingleton SK. The effect of antibiotic therapy on recovery of intracellular bacteria from bronchoalveolar lavage in suspected ventilator-associated nosocomial pneumonia. Chest 1993; 103: 541-546.

31. Chastre J, Fagon J-Y. Invasive diagnostic testing should be routinely used to manage ventilated patients with suspected pneumonia. Am J Respir Crit Care Med 1994; 150: $570-574$. 